\title{
Diabetic mastopathy: a diagnostic challenge
}

\author{
NATASHA SHRIKRISHNAPALASURIYAR, MICHAEL ATKINSON, ATUL KALHAN, PHILIP EVANS
}

\section{Introduction}

Diabetic mastopathy (DMP) is a rare benign fibroinflammatory disease of the breast (prevalence $0.6-13 \%)^{1}$ most commonly seen in premenopausal women with type 1 diabetes (T1DM) who may have other diabetes-related complications. It is challenging to distinguish DMP from breast carcinoma based on clinical assessment and radiological investigations alone. Definitive diagnosis relies on histopathological evaluation of tissue biopsies. We describe the case of a patient with T1DM who presented with a left-sided breast mass and underwent evaluation for possible breast carcinoma leading to significant emotional and physical distress to the patient and her family.

Key words: diabetic mastopathy (DMP), type 1 diabetes, type 2 diabetes, breast, breast lump, breast disease, benign

\section{Case report}

A 28-year-old woman who was diagnosed with T1DM in infancy presented to her general practitioner in 2015 with a 6-month history of an enlarging, painful, non-cyclical left-sided breast lump. She had a longstanding history of poor glycaemic control $\left(\mathrm{HbA}_{1 \mathrm{c}}\right.$ $103 \mathrm{mmol} / \mathrm{mol}$ ) with proliferative retinopathy. She was on a premixed insulin (30:70). She had previously suffered from optic neuritis. There was no family history of breast cancer; however, her mother was investigated for a breast lump which was subsequently found to be a fibroadenoma.

On clinical examination she had a tender, mobile, irregular $5 \mathrm{~cm}$ mass in her left breast. There was no associated nipple discharge, skin or breast changes, and no lymphadenopathy. In view of this suspicious breast lump, further radiological investigations were arranged. An ultrasound scan demonstrated an ill-defined hypoechoic mass (Figure 1A). Core biopsies containing breast tissue with dense fibrosis were obtained (Figure 1B). Histological examination revealed no evidence of ductal carcinoma in situ or invasive malignancy; however, there were areas of focal perivascular chronic inflammation in keeping with a diagnosis of DMP (Figure 2).

Department of Diabetes and Endocrinology, Royal Glamorgan Hospital, UK

Address for correspondence: Dr Natasha Shrikrishnapalasuriyar Diabetes Department, Royal Glamorgan Hospital, Llantrisant CF72 8XR, UK

E-mail: natashashrikrishna@doctors.org.uk

Br J Diabetes 2018;18:32-34

https://doi.org/10.15277/bjd.2018.169
Figure 1. Ultrasound scan showing a) hypoechoic area of breast tissue consistent with diabetic mastopathy and b) fine needle biopsy

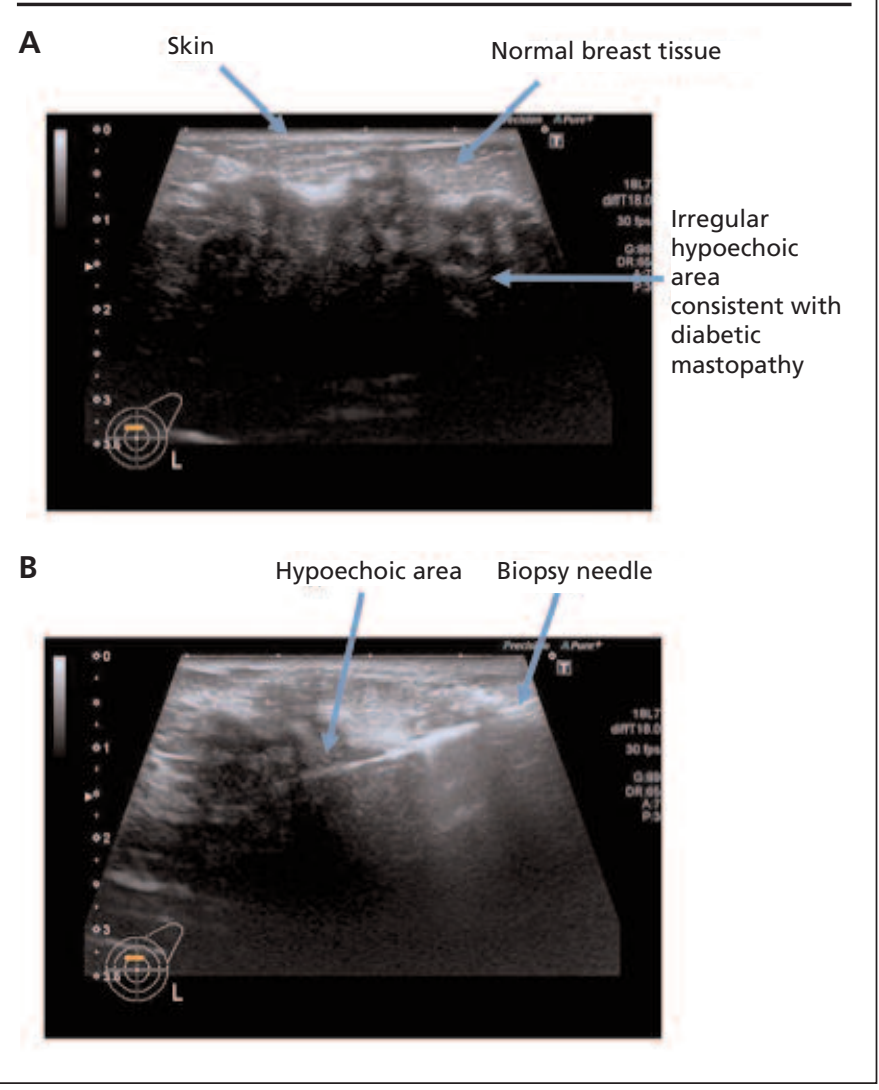

She was followed up in breast clinic 3 months later, by which time the breast mass had reduced in size. A conservative management plan of self-examination with early re-presentation if any changes were noted was agreed mutually by the breast surgical team and the patient. To date, she remains well with no further recurrence of the breast mass.

\section{Discussion}

DMP was initially described in 1984 by Soler and Khadori in women under the age of 30 years who had T1DM with complications such as retinopathy or nephropathy. The prevalence of this condition has been quoted as $1-13 \%$ among women of reproductive age with T1DM and accounts for less than $1 \%$ of benign breast conditions. ${ }^{2}$ This condition is not exclusively seen in T1DM. There is a weaker association between DMP and 
Figure 2. Histological Specimen

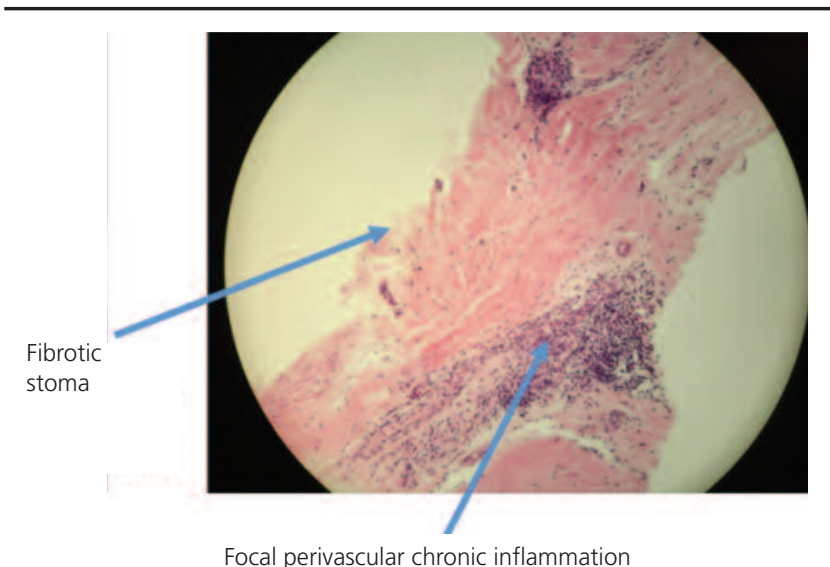

T2DM. When associated with other autoimmune conditions such as systemic lupus erythematous and Hashimoto's disease, DMP has been described as lymphocytic mastopathy due to associated lymphoid infiltrates composed of B cells. ${ }^{3}$ Patients classically present with a painless, hard and irregular mass within the breast tissue.

\section{Pathogenesis}

The pathogenesis of DMP is incompletely understood, although various theories have been proposed. One such theory proposes that, in patients with diabetes, increased glycosylation and intermolecular cross-linkages result in the formation of collagen which is resistant to degradation.4,5 Sternberg et al hypothesised that the formation of glycosylated end products was a consequence of a hyperglycaemia-induced autoimmune response leading to B cell proliferation and autoantibody production. ${ }^{4}$ The associated cytokine release acts as a growth factor leading to matrix enlargement. It has also been suggested that exogenous insulin can cause antibody development with consequent crossreactivity. This pathological feature is in contrast to patients without diabetes who develop lymphocytic mastitis, which typically demonstrates a higher proportion of T cells. ${ }^{6}$ The reason for the predominance of $B$ cells in DMP remains unclear. There is an association between Hashimoto's thyroiditis and Sjögren's syndrome with B cell non-Hodgkin's lymphoma of the thyroid gland and stomach; however, there is no associated risk with lymphocytic mastitis or DMP. ${ }^{3}$

\section{Diagnosis}

Mammography of DMP shows diffuse dense glandular tissue, but current imaging techniques are unable to distinguish between mastopathy and malignancy. An ultrasound-guided fine needle aspiration or core biopsy to demonstrate the characteristic histology remains the investigation of choice. Histological features include lymphocytic lobulitis, ductitis and perivasculitis with stromal keloid fibrosis. Histological criteria for the diagnosis of DMP, as defined by Siedman et $a l_{1}^{7}$ include: (1)

\section{Key messages}

- Diabetic mastopathy is a benign condition which may be present in up to $13 \%$ of women with type 1 diabetes mellitus

- Diagnosis is based on histology as it may be clinically and radiologically indistinguishable from breast carcinoma

- There is a high risk of recurrence following attempted surgical excision

- There is no increased risk of development of breast carcinoma

collagenous stroma with keloid-like features and an increased concentration of spindle cells; and (2) mature lymphocytes clustered around small blood vessels, lobules and ducts.

\section{Prognosis}

Whilst there exists a single case report describing the development of breast carcinoma in a patient with $\mathrm{DMP}^{8}$ there is no convincing evidence to suggest any increased risk of developing malignant breast cancer. Unilateral lesions may be managed with excisional biopsy. A 2017 literature review of surgical management of DMP found that, of 178 cases of DMP, 160 patients (89.9\%) underwent lumpectomy, four patients (2.2\%) had mastectomies and two patients underwent excision as part of a reduction mammoplasty. The report by Agochukwu and Wong ${ }^{9}$ describes an apparently unique case in which bilateral DMP was treated with bilateral nipple-sparing mastectomies due to pain and concerns regarding limitations of future cancer detection. Despite the benign nature of DMP, recurrence is likely in the same or contralateral breast. Approximately $60 \%$ of cases recur after surgical excision and often involve more extensive breast tissue at the same site. ${ }^{9}$ Therefore, the recommendations are for asymptomatic histologically-confirmed DMP to be managed conservatively with annual follow-up. ${ }^{6}$ It is essential for patients to be educated in performing regular breast self-examination. If a new breast lump or unusual clinical features develop on a background of DMP - for example, skin changes or lymphadenopathy - a repeat core biopsy should be performed. Where the clinical and histological characteristics of a new breast lump are similar to previous DMP, conservative management is recommended. Despite this, most cases in the literature which describe subsequent breast lumps on a background of DMP were treated with further excisions. ${ }^{9}$

\section{Conclusion}

DMP is a benign breast disease observed in approximately one in eight women with T1DM. The most important differential diagnosis is breast carcinoma, from which it is indistinguishable both clinically and radiologically. A histological sample is therefore required to make the correct diagnosis. The high recurrence rate following excision has led to a conservative management 
approach in most histologically confirmed cases of DMP. Whilst the evidence suggests there is no increased risk of breast cancer or stromal neoplastic disease in patients with DMP, each new mass requires careful evaluation and appropriate investigations.

Acknowledgements We would like to thank Dr K Gower Thomas, Dr J Pollitt, Dr S Bolt and Dr E Youd for helping with the radiological images and histopathology for this article.

\section{Conflict of interest None \\ Funding None}

\section{References}

1. Sankaye S, Kachewar S. Diabetic mastopathy. Australas Med J 2012;5: 296-9. http://dx.doi.org/10.4066/AMJ.2012.1247

2. Soler NG, Khardori R. Fibrous disease of the breast, thyroiditis, and cheiroarthopathy in type 1 diabetes mellitus. Lancet 1984;1(8370):193-5.

3. Valdez R, Thorson J, Finn WJ, et al. Lymphocytic mastitis and diabetic mastopathy: a molecular, immunophenotypic, clinicopathologic evaluation of 11 cases. Modern Pathol 2003;16:223-8.

4. Sternberg M, Cohen-Forterre L, Peyroux J. Connective tissue in diabetes mellitus: biochemical alterations of the intercellular matrix with special reference to proteoglycans, collagens and basement membranes. Diabete Metab 1985;11:27-50.

5. Tomaszewski JE, Brooks JS, Hick D, Livolsi VA. Diabetic mastopathy: a distinctive clinicopathological entity. Hum Pathol 1992;23:780-6.

6. Hunfeld KP, Bassler R. Lymphocytic mastitis and fibrosis of the breast in long-standing insulin-dependent diabetics. A histopathologic study on diabetic mastopathy and report of ten cases. Gen Diagn Pathol 1997; 143:49-58.

7. Siedman JD, Schnaper LA, Philips LE. Mastopathy in insulin-requiring diabetes mellitus. Hum Pathol 1994;25:819-24.

8. Mackey SP, Sinha S, Pusey J, et al. Breast carcinoma in diabetic mastopathy. Breast J 2005;14:392-8. http://dx.doi.org/10.1016/j.breast.2004.09.016

9. Agochukwu NB, Wong L. Diabetic mastopathy. A systematic review of surgical management of a rare breast disease. Ann Plast Surg 2017 78:471-5. http://dx.doi.org/10.1097/SAP.0000000000000879. 